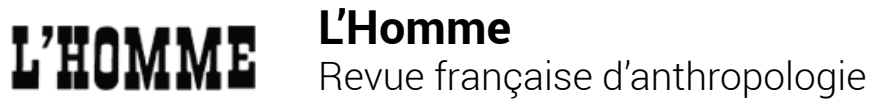

164 | octobre-décembre 2002

Histoire, littérature et ethnologie

\section{Jean Pouillon (1916-2002)}

\section{La rédaction}

\section{(2) OpenEdition \\ Journals}

\section{Édition électronique}

URL : https://journals.openedition.org/lhomme/14372

DOI : 10.4000/lhomme.14372

ISSN : 1953-8103

\section{Éditeur}

Éditions de l'EHESS

\section{Édition imprimée}

Date de publication : 1 décembre 2002

Pagination : 7-8

ISBN : 2-7132-1775-X

ISSN : 0439-4216

\section{Référence électronique}

La rédaction, « Jean Pouillon (1916-2002) », L'Homme [En ligne], 164 | octobre-décembre 2002, mis en ligne le 27 mars 2008, consulté le 22 avril 2022. URL : http://journals.openedition.org//homme/14372 ; DOI : https://doi.org/10.4000//homme.14372 


\section{Jean Pouillon (1916-2002)}

OMMENCÉ un 2 décembre 1916 à Saint-Maur-des-Fossés et surtout infléchi lors de son entrée au comité de rédaction des Temps Modernes en 1945, puis à la tête de L'Homme en 1960, le "grand parcours" de Jean Pouillon, selon l'heureuse formule de Claude Tardits, s'est interrompu à Paris le 8 avril 2002. Il repose désormais au cimetière du Montparnasse à quelques mètres de son ami et condisciple Jacques-Laurent Bost et de celui dont il fut l'un des plus proches, Jean-Paul Sartre. De la philosophie à l'ethnologie en faisant un détour par les romans de Stendhal et de Faulkner, ou par le cinéma américain, des Temps Modernes à L'Homme en passant par la Nouvelle revue de psychanalyse et Le Temps de la réflexion, de l'exitentialisme sartrien au structura-

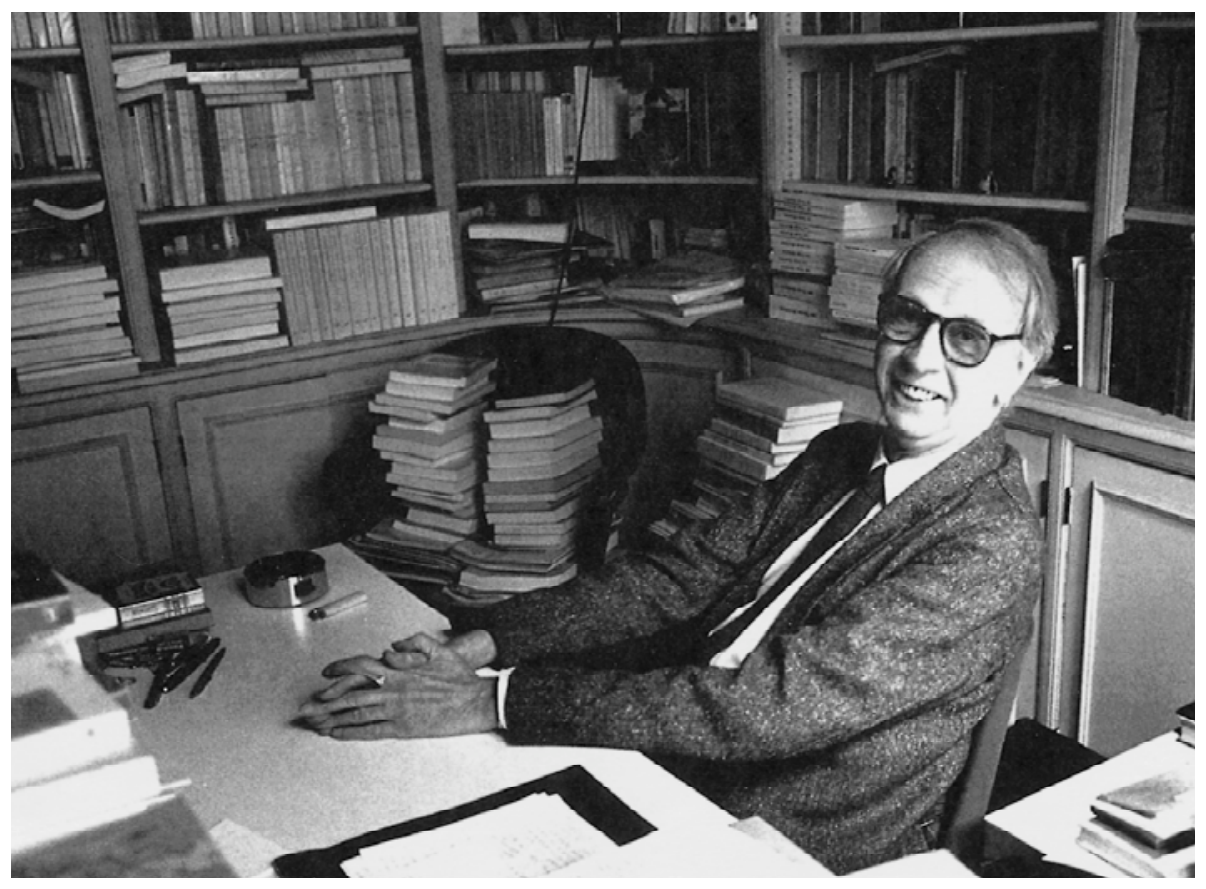


lisme lévi-straussien, le parcours est grand, bien sûr, non seulement par la diversité des chemins empruntés mais parce quil fut d'abord des plus singuliers.

Jean Pouillon représente en effet un cas à part dans l'anthropologie française de ces demières décennies, comme l'est du reste son cuvre, protéiforme mais concise, toute faite de rigueur mais aussi de malice épistémologique : en témoignent les textes d'auteurs venus d'horizons variés, les réflexions de chercheurs issus de générations différentes qui, rassemblés dans un précédent numéro de L'Homme ("Histoire d'homme: Jean Pouillon", $n^{\circ} 143,1997$ ), s'attachent à l'évoquer, la fouiller, l'évaluer, la prolonger, rendant ainsi un captivant hommage à celui qui, non content de l'a vair édifiée avec la clarté et la justesse d'écriture dont il avait le secret, seétait également et souvent penché, avec les mêmes exigences, sur leurs propres écrits. Ce volume fut composé au moment de sa mise à la retraite de la direction d'une revue savante et institutionnelle quill avait contribué à fonder et qüil dirigea pendant trente-six ans alors qu'il ne releva statutairement d'aucun organisme de recherche officiel ni d'aucun établissement d'enseignement supérieur. Tel fut peut-être, pour cet homme friand de paradoxes logiques, le premier d'entre eux, celui-ci existentiel: avoir été, comme le remarque Claude Lévi-Strauss, "la consciente vigilante des ethnologues" sans jamais être devenu académiquement l'un d'eux. Secrétaire des débats de l'Asemblée nationale depuis 1946, Jean Pouillon, qui y fit carrière, avait su mettre à profit la flexibilité d'emploi du temps que lui procurait, aimait-il dire, "ce métier d'imbécile qui demande de l'intelligence", pour sappliquer, que ce soit de son "perchoir» à l'Assemblée, dans son bureau au Laboratoire d'anthropologie sociale ou sur ses terrains ethnographiques au Tchad et en Éthiopie, à rendre intelligibles les faits sociaux, religieux ou politiques les plus déconcertants (ou les plus banals), si ce n'est les dimensions les plus retorses (ou les plus convenues) de la pensée humaine. Sans doute est-ce cet appétit d'éclaircir, de comprendre, d'analyser qui l'amena, au tra vers des milliers de pages qu'il dut lire, des milliers de paroles quil dut écouter, des non moins nombreuses attitudes quil dut décrypter, à rechercher un peu d'ordre, à cerner quelques invariants, et à se plonger très tôt dans l'euvre de Claude Lévi-Strauss, quill dévo ra d'un coup et qui lui apporta une méthode.

C'est au structuralisme de celui-ci, dont en 1956 il fut l'un des commentateurs les plus pénétrants, quil fait toujours référence près de trente ans plus tard, précisément le 14 novembre 1983 lors d'une conférence prononcée devant les membres de l'Académie des sciences morales et politiques. Nous avons tenu à la reproduire ici-même, comme pour mieux rappeler, mieux faire sentir, mieux rendre présents une fois encore dans nos colonnes le ton de sa voix, l'élégance et l'humour de son expression, la précision de sa pensée. Nous remercions Michel Izard de nous avoir signalé ce texte qui ne fut pas répertorié dans la bibliographie de Jean Pouillon établie à l'occasion de la préparation du numéro d'hommage cité plus haut. Nous remenions également le secrétaire général de la Revue des sciences morales et politiques de nous avoir autorisés à le republier. 